\title{
Life cycle analysis of HCNG light-duty vehicle demonstration project
}

\author{
Pralhad Gupta ${ }^{1}$, Ye Wu ${ }^{2}$, \\ Xiaoyi $\mathrm{He}^{2}$, Weilin Zhuge ${ }^{1}$, \\ Fanhua Ma ${ }^{1}$
}

\footnotetext{
${ }^{1}$ State Key Laboratory of Automotive Safety \& Energy, Department of Automotive Engineering, Tsinghua University, Beijing-100084, Beijing, Hebei, China.

${ }^{2}$ School of Environment, Tsinghua University, Beijing-100084, Beijing, Hebei, China. e-mail: pgupta.tsinghua@yahoo.com, zhugewl@tsinghua.edu.cn, mafh@tsinghua.edu.cn,ywu@tsinghua.edu.cn, hexy@mails.tsinghua.edu.cn
}

\begin{abstract}
The demonstration is an effective initiative to bridge the gap between a premature technology and its largescale commercialization. A systematic method of LCA was used to perform the well-to-wheel analysis of a CNG light-duty truck operated with $0 \%, 15 \%$, and $30 \%$ blends of hydrogen with compressed natural gas fuel under the system boundary of "per vehicle km". The GREET simulation was performed on GREET_1 (Excel Series_2017) to evaluate hydrogen production pathways with numerous parametric assumptions adopted to base the study in the context of China. Resource use, fossil energy use, GHG emission, and major air pollutants namely $\mathrm{NO}_{\mathrm{x}}$ and $\mathrm{PM}$ were studied. The idea was to demonstrate the effects of hydrogen addition throughout the entire fuel cycle of end-use of HCNG in an $\mathrm{HCNG}^{\circledR}$ LDV. The hydrogen blend of $30 \%$ with conventional CNG decreased the well-to-wheel GHG emission compared with 0\%HCNG by 32.982\%, $29.275 \%$, and $9.694 \%$ with hydrogen pathways such as solar, biomass, and coke oven gas, respectively. Moreover, for $30 \% \mathrm{HCNG}$ (Conv.NG), the well-to-wheel total energy consumption was increased by $15.176 \%$, and $15.719 \%$ for solar and biomass-based pathways, respectively. However, although the energy consumption was increased for solar and biomass-based 15\%HCNG and 30\% HCNG pathways compared with $0 \% \mathrm{HCNG}$, the feedstock used was renewable and qualitatively cleaner. The worst scenario was found in the form of $30 \% \mathrm{HCNG}$ (Conv.NG) with grid electrolysis pathway which showed $60.648 \%$ increment in WTW GHG and $75.479 \%$ increment in WTW total energy compared with baseline $0 \%$ HCNG (Conv.NG). The booming renewable electricity generation and availability of a tremendous amount of coke oven gas as by-products from coking industries in China can establish a prospective platform for sustainable hydrogen economy in China and is supposed to promote the commercialization of HCNG vehicles in future.
\end{abstract}

Keywords: demonstration, life cycle analysis, $\mathrm{HCNG}^{\circledR}$, well-to-wheel, LDV, GREET

\section{INTRODUCTION}

\subsection{Research background}

Tremendous works have been done to achieve performance and emission evaluation of HCNG vehicles since past few decades. Interestingly, most of the scientific research works have claimed numerous advantages of hydrogen addition to compressed natural gas fuel at optimized engine's operating conditions. The $20 \%$ hydrogen enrichment $\left(\mathrm{HCNG}^{\circledR}\right)$ requires no severe engine's modifications apart from slight adjustments in the fuel supply system and operating conditions. It is also obvious to find out a slight reduction in brake specific fuel consumption and exponentially decreased air pollutants and tailpipe emissions. However, it has not achieved commercialization phase till now and one thing that hinders its promotion is the 'hydrogen economy' itself. The purpose of this investigation was to perform a simplified version of life cycle analysis for $\mathrm{HCNG}^{\circledR}$ demonstration project which presents the full picture of environmental impacts of $\mathrm{HCNG}^{\circledR}$ aimed for light-duty vehicle usage and has been compared with counterpart baseline CNG vehicle. Hydrogen is not a primary energy source, rather it is an energy carrier. Henceforth, the feedstock for hydrogen production plays a vital role in the realization of cleaner and efficient HCNG vehicle technology. The stringent emission and fuel economy requirements for light-duty vehicle operations demand the use of clean-burning alternative 
fuels such as compressed natural gas. The ultimate goal of this work was to find the amount of energy $(\mathrm{MJ} / \mathrm{km})$ required 'per vehicle $\mathrm{km}$ ' and grams of $\mathrm{CO}_{2 \text {,equivalent }}(\mathrm{GWP})$ per vehicle $\mathrm{km}(\mathrm{g} / \mathrm{km})$. Results give the understanding of two perspectives; qualitative and quantitative. Generally speaking, researchers proved that the 20-30\% HCNG overpasses the dominance of CNG in three major tiers: reduction on fuel consumption, air pollutants, and as greenhouse gas emissions depending upon the accuracy of operating conditions.

\subsection{Previous works}

In 2007, [19] suggested that China surpassed the USA as the world's largest contributor to $\mathrm{CO}_{2}$ emissions. The rapid increase in economic growth rate, urbanization, and industrialization over the past few decades (in particular for last 10 years) in China has resulted in the tremendous booming of transportation services and automobile markets. Currently, China is the world's largest automobile market and among one of the fastest growing nations in the global automobile market according to [9]. Compared to conventional buses, AFVs offer better performance and reduced GHG emission. However, only half of the AFVs analyzed proved to be fulfilling dual benefits (energy saving \& lower GHGs) [14]. According to Anadolu Agency [17], China is currently leading with the most natural gas vehicles. It has been pointed out that China has the largest population of natural gas vehicles globally followed by Iran and India at the end of 2017, according to the current statistics of NGV Global.

Hydrogen is a zero-emitter fuel with a very fast laminar burning speed and wide range of flammability which confirms it as one of the superlative energy carrier to enhance the slow burning rate of CNG at lean burn and constitute tremendous possibilities to empower the present generation internal combustion engines together with compressed natural gas which sounds promising at the current era of transition to a greener future transportation [12]. $\mathrm{NO}_{\mathrm{x}}, \mathrm{CO}, \mathrm{NMHC}, \mathrm{CH}_{4}$ emissions, and $\mathrm{BSFC}$ decreases by $51 \%, 36 \%, 47 \%$, and $7 \%$, respectively whereas the maximum power remains the same with $\mathrm{HCNG}^{\circledR}(20 \% \mathrm{HCNG})$ as compared to baseline CNG engine (6.234L-SI) [11]. The experimental evaluation of a 6-cylinder (6.014L) natural aspirated compressed natural gas engine optimized with $18 \%$ hydrogen addition and tested according to a simulated city driving cycle in accordance with ETC specifications equipped with 600-hours of endurance testing (15 models each cycle of 100 hours) demonstrated that $18 \%$ hydrogen blended CNG results in reduction of $\mathrm{CO}, \mathrm{THC}$, and $\mathrm{CH}_{4}$ by $39 \%, 25 \%$, and $25 \%$, respectively as well, on the other hand, increases $\mathrm{NO}_{\mathrm{x}}$ by $32 \%$. The engine power was not affected significantly by the complete 600 -hours of an endurance test with $18 \%$ hydrogen enrichment. The emission results over 600-hours of endurance testing with $18 \%$ HCNG met Euro IV emission standards for heavy-duty engines [16].

Road tests carried out by running fixed tracks $\left(60 \mathrm{~km}, V_{\text {mean }}=20 \mathrm{kmph}, \mathrm{V}_{\max }=40 \mathrm{kmph}\right)$ which may be considered as urban and sub-urban driving cycles for a fleet of two buses tested with 5\% HCNG on a sub-urban track whereas the other with $8 \mathrm{~m}$ length tested with various volumetric fractions of hydrogen such as $5 \%, 10 \%, 15 \%, 20 \%$ and $25 \%$ with CNG. The buses include Vivacity CNG Mercedes (turbo-charged) with 6 cylinders $(6880 \mathrm{CC})$ and rated power as $170 \mathrm{~kW}$. This work demonstrated that $5 \% \mathrm{HCNG}$ improved energy consumption by $4 \%$. The $25 \% \mathrm{HCNG}$ produced the largest reduction of $\mathrm{CO}_{2}$ by $25 \%$ compared with baseline CNG operation. The levels of $\mathrm{HC}$ emission were constant and could not meet the EEV limits. $\mathrm{NO}_{\mathrm{x}}$ reduced by $47 \%$ with 5\% HCNG [3]. A chassis dynamometer test bench experiment performed on a passenger car with L4-SI (PFI) engine equipped with a TWC as per NEDC cycle procedure highlighted the effects of $12 \%$ hydrogen addition with compressed natural gas on engine efficiency and emissions without changing ignition timing. Results showed that $\mathrm{CO}$ and $\mathrm{CO}_{2}$ were reduced by $19 \%$ and $3 \%$ respectively whereas $\mathrm{HC}$ was almost unchanged. The amount of $\mathrm{NO}_{\mathrm{x}}$ increased by $70 \%$. No significant changes occurred in fuel consumption on both bases; mass and energy. Therefore, this work made an obvious explanation that it is impossible to enhance engine performance and emission without a proper hydrogen fraction and optimum spark timing [18].

One of the biggest challenges with the implementation of $\mathrm{HCNG}^{\circledR}$ is associated with the development of supporting infrastructure. Therefore, HCNG allows for initial use of hydrogen while taking advantage of the current CNG infrastructure. It also allows for the hydrogen infrastructure to slowly become established until the production and efficiency demands can be met for the hydrogen economy. Although there is currently a huge number of research works taking place regarding $\mathrm{HCNG}$, there are certainly many steps to take before wide-spread implementation can occur [10]. In this regard, an LCA of a demonstration project for a vehicle use of hydrogen blended natural gas performed by [8] accesses and compares the environmental aspects of natural gas, HCNG with $15 \%$ and $30 \%$ by volume, and hydrogen as vehicular fuels within the scope of a demonstration project. Two different types of light-duty vehicles with internal combustion engines 
were tested in this study. The general conclusion revealed by this study claims that the potential environmental impact from the fuel supply chain considerably increases towards a hydrogen share of $100 \%$ in the fuel.

The transition to new fuel chains demands large investments and long time frames for adjustments since the adaptation of fuel supply, retail stations, and vehicles is required. Furthermore, the transition strategy must endorse a trade-off between environmental benefits, costs and implementation obstacles which are obvious. The author commented in a very witty way HCNG could be a sustainable solution for the chickenor-the-egg problem of which comes first-the fuel cell vehicles or the hydrogen infrastructure to fuel them; it arises from the fact that existing natural gas networks could be used for the distribution of HCNG. The author also added that no significant changes in the performance trends of modified HCNG 15\% and HCNG 30\% compared with baseline $\mathrm{CNG}$ vehicle. However, the corresponding fleet of hydrogen vehicles would have the best environmental performance [8]. Greener hydrogen can support a significant reduction of $\mathrm{CO}_{2}$ emissions. However, if the goal is ultimately $\mathrm{CO}_{2}$ reduction, $\mathrm{HCNG}$ may not be an effective choice as it offers only $10 \%$ reduction in $\mathrm{CO}_{2}$ emissions which can be achieved in many parts of the world just by replacing CNG with biogas. Lastly, this study also proved that HCNG is best suited for the primary goal of air pollution reduction rather than $\mathrm{CO}_{2}$ reduction [13].

Currently, there is no commercial production of hydrogen energy in China and is limited to the petroleum industry and small-scale production only. [2] revealed that the hydrogen production amount in China is about 12.42 million tonnes per year. It is mostly produced from coal, natural gas and oil and accounts for $57.4 \%, 23 \%$, and $19.7 \%$ of total production. The author mentions that $75.8 \%$ of the hydrogen is consumed for ammonia refining, whereas $10.5 \%$ and $13.7 \%$ for methanol and oil refining respectively. Lastly, it has been pointed out that 5.7 million tons of by-product hydrogen could fuel 17.7 million fuel cell vehicles in China [2].

A study carried out to perform WTW study of hydrogen fuel cell vehicle pathways in Shanghai with ten hydrogen pathways in Shanghai founded that the two naphtha-based hydrogen pathways showed about $20 \%$ reduction in WTW petroleum. All the hydrogen pathways also showed significant reductions in WTW urban criteria pollutants except the two pathways which resulted in the increased amount of $\mathrm{SO}_{\mathrm{x}}$ emissions. The NG-based hydrogen pathways proved to be the best in terms of WTW energy efficiency and the electrolysis-based pathways showed the worst characteristics. The WTW energy efficiencies of hydrogen pathways from naphtha and hydrogen pathways from coal are between lie between NG-based pathways and electrolysis pathways. The pathways from naphtha have higher energy efficiencies than the pathways from coal. Moreover, changes in WTW GHG emissions have nearly identical results to changes in WTW energy use. However, WTW criteria pollutants such as VOCs and $\mathrm{CO}$ were found to be reduced for all pathways whereas $\mathrm{NO}_{\mathrm{x}}, \mathrm{PM10}$, and $\mathrm{SO}_{2}$ have certain reductions in NG and crude oil-based hydrogen pathways, but have a significant increase in electrolysis and coal-based pathways [5].

In order to realize the extensive commercialization and marketization of HCNG vehicles, the demonstration project is a pre-commercial initiative and formative period. The formative period is categorized into two further classifications: experimental phase, and take off phase. The experimental phase is a roadway to technological development and is interlinked with initial uncertainties. The continuous learning and knowledge curve is a possible outcome of an experimental phase. The "take-off" phase is related to the formative of networks. The word 'network' is a collective cluster of suppliers, users, research institutes, universities, organizations, and professionals. The demonstration project is aimed at 2-tier goals. Namely, they are direct goals and indirect goals. The direct goals include profits, technological success, etc. whereas the indirect goals include technological development in all three main spectrums of sustainability: technology, economy, and society [8].

\section{MATERIALS AND METHODS}

This research work used a typical life cycle approach for well-to-wheel analysis (excl. vehicle lifecycle). According to the International Organization for Standardization (ISO) $14040 \& 14044$ series guidelines for conducting an LCA study, four phases were identified i.e. (i) goal \& scope of definition, (ii) inventory analysis (LCI), (iii) impact assessment (LCIA), and (iv) Interpretation.

\subsection{Definition of goal \& scope}

Life cycle analysis of HCNG demonstration project in Chinese context based on an LCA framework of 'fuel cycle WTW'. 


\subsubsection{Product definition}

\section{HCNG light-duty truck [7]}

The vehicle operation data has been obtained from U.S. Department of Energy FreedomCAR \& Vehicle Technologies Program-Hydrogen and Hydrogen/Natural Gas Station and Vehicle Operations -2006 Summary Report by [7], Idaho National Laboratory. The detailed information about vehicle operation has been tabulated in preceding section 'Data'.

\subsubsection{System boundary}

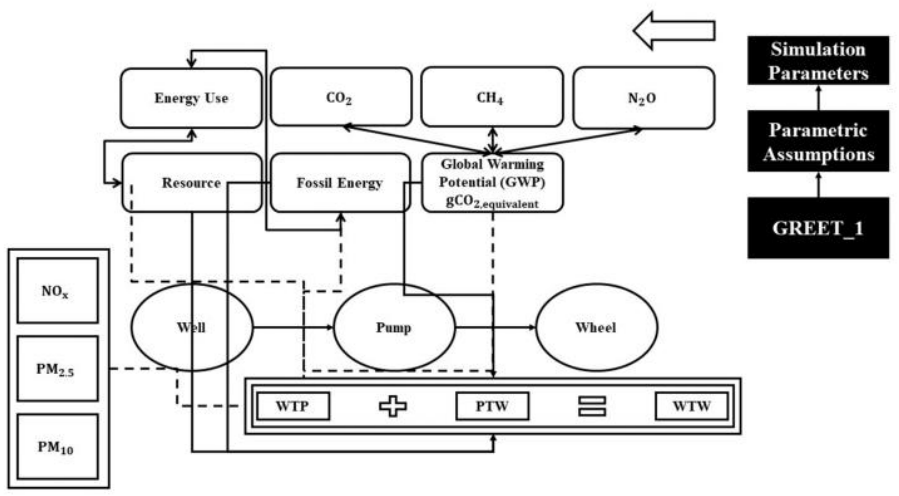

Figure 1: System boundary

Figure 1 shows the system boundary of this study. GREET_1 (2017) excel series was used for wellto-pump simulation of gaseous hydrogen from the various feedstock. The well-to-pump data for compressed natural gas pathway was sourced from [15] \& [1]. The parametric input data assumptions prior to GREET simulation were made on GREET_1 to base this study in the Chinese context. The pump-to-wheel data was sourced from [7]. The well-to-pump data of gaseous hydrogen and CNG were integrated to form $\mathbf{W T P}_{\mathbf{x H C N G}} \mathbf{L C I}$ (x indicates \% of hydrogen in the mixture fuel by using a principle of weighted average on an

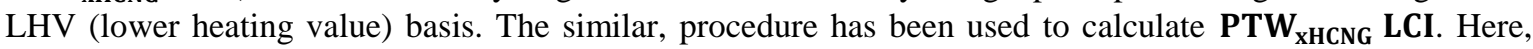
LCI indicates life cycle inventory for example; resource use, fossil use, GHG and air pollutants. $\mathbf{C O}_{2}, \mathbf{C H}_{4}$, and $\mathbf{N}_{2} \mathbf{O}$ were combined according to their GWP-100 years based on IPCC report. The method suggested by [6] has been used to evaluate the well-to-wheel results. Moreover, fossil energy use was evaluated for the well-to-pump stage of gaseous hydrogen pathways to evaluate the potential benefits of renewable hydrogen pathways. $\mathbf{L D V}_{\mathbf{s}}$ are one of the major sources of $\mathbf{N O}_{\mathbf{x}}$ and PM emissions in China due to the dominance of fossil fuel. In this regard, $\mathbf{G H}_{2}$ was assessed in terms of WTP $\mathbf{N O}_{\mathbf{x}}$ \& PM emissions.

\subsubsection{Functional unit}

A functional unit is defined for comparison of life cycle inventory use (LCI) for both baseline CNG and HCNG. LCI refers to resource use, fossil use, GHG, urban air pollutants, etc. The functional unit assigned may differ from a study to another and is basically defined for both WTP and PTW stages differently.

- $\quad$ Per MJ energy in fuels

$\mathrm{WTP}_{\text {Resource }}=\frac{\mathrm{MJ}}{\mathrm{MJ}_{\mathrm{f}}} ; \mathrm{WTP}_{\mathrm{GHG}}=\frac{\mathrm{gCO}_{2 \mathrm{e}}}{\mathrm{MJ}_{\mathrm{f}}}$

- $\quad$ Per vehicle $\mathrm{km}(1$ vehicle $\mathrm{km})$

$\mathrm{PTW}_{\text {Resource }}=\frac{\mathrm{MJ}}{\mathrm{km}}$ (fuel economy); $\mathrm{PTW}_{\mathrm{GHG}}=\frac{\mathrm{MJ}}{\mathrm{km}} ; \mathrm{WTW}_{\text {Resource }}=\frac{\mathrm{MJ}}{\mathrm{km}} ; \mathrm{WTW}_{\mathrm{GHG}}=\frac{\mathrm{gCO}_{2 \mathrm{e}}}{\mathrm{km}} ;$

Note: The functional unit for air pollutants was chosen similar to that of GHG mentioned above.

\subsection{Data}

The data can be categorized into two groups of a fuel cycle: (i) well-to-pump (WTP), \& (II) pump-to-wheel (PTW). 


\subsubsection{Pump-to-wheel}

The pump-to-wheel vehicle operation data was extracted from [7]. The complete demonstration of HCNG is out of the context of the chosen study framework. The test description and vehicle specifications have been shown in the diagram shown in Figure 2.

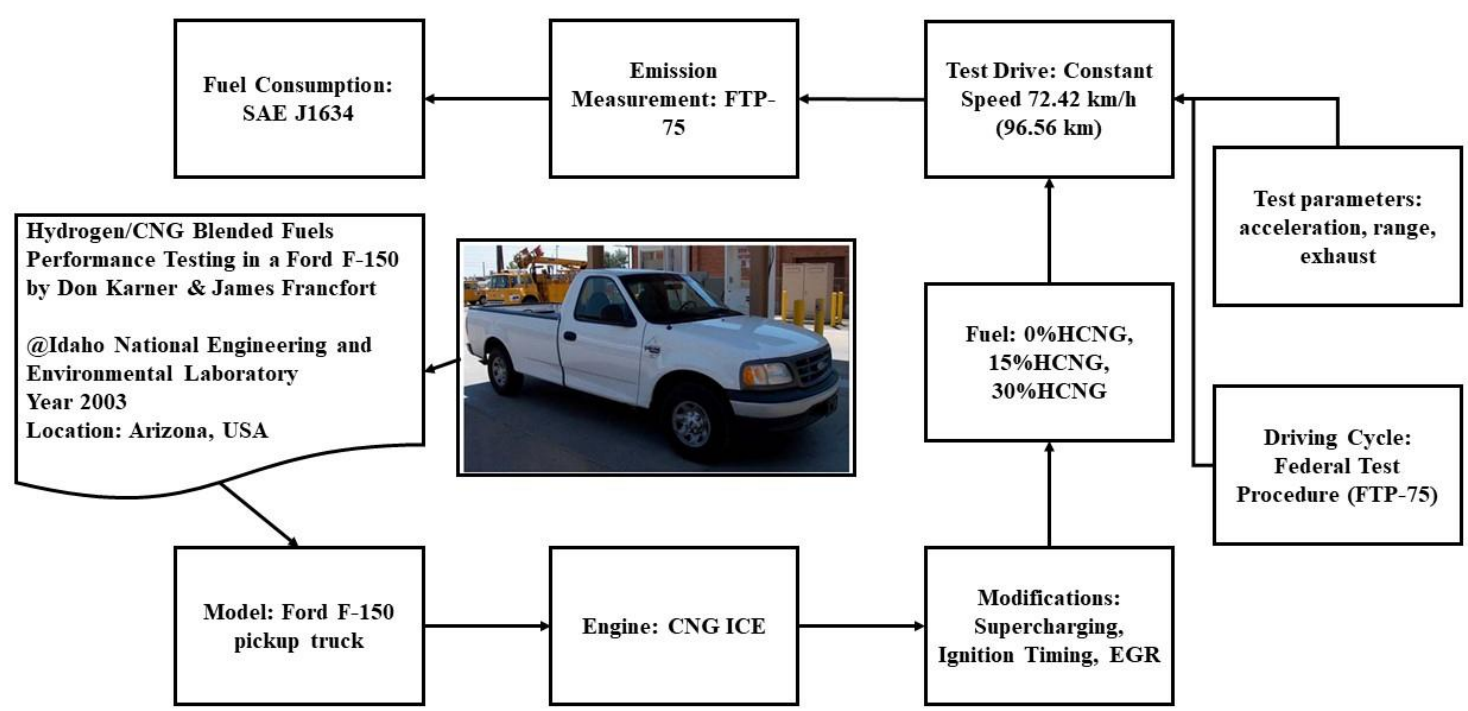

Figure 2: Pump-to-wheel light-duty vehicle demonstration

Table 1: The light-duty vehicle demonstration pump-to-wheel performance and emission data

\begin{tabular}{l|l|l|l|l|l|l|l|}
\hline FUEL & $\begin{array}{l}\text { FUEL } \\
\text { ECONOMY } \\
(\mathbf{M J} / \mathbf{K M})\end{array}$ & $\mathbf{C O}_{2}\left(\frac{\mathbf{g}}{\mathbf{k m}}\right)$ & $\mathbf{C O}\left(\frac{\mathbf{g}}{\mathbf{k m}}\right)$ & $\mathbf{C H}_{\mathbf{4}}\left(\frac{\mathbf{g}}{\mathbf{k m}}\right)$ & $\mathbf{N O}_{\mathbf{x}}\left(\frac{\mathbf{g}}{\mathbf{k m}}\right)$ & $\mathbf{N M H C}\left(\frac{\mathbf{g}}{\mathbf{k m}}\right)$ & $\mathbf{H C}\left(\frac{\mathrm{g}}{\mathbf{k m}}\right)$ \\
\hline CNG & 5.48 & $2.94 \mathrm{E} 2$ & $3.52 \mathrm{E}-1$ & $7.95 \mathrm{E}-2$ & $6.84 \mathrm{E}-2$ & $1.43 \mathrm{E}-2$ & $1.07 \mathrm{E}-1$ \\
\hline $15 \%$ HCNG & 5.64 & $2.81 \mathrm{E} 2$ & $2.90 \mathrm{E}-1$ & $8.20 \mathrm{E}-2$ & $7.71 \mathrm{E}-2$ & $1.55 \mathrm{E}-2$ & $1.11 \mathrm{E}-1$ \\
\hline $30 \%$ HCNG & 5.43 & $2.78 \mathrm{E} 2$ & $2.63 \mathrm{E}-1$ & $8.57 \mathrm{E}-2$ & $7.83 \mathrm{E}-2$ & $8.08 \mathrm{E}-3$ & $1.09 \mathrm{E}-1$ \\
\hline
\end{tabular}

Table 2: The well-to-pump data for natural gas pathways

\begin{tabular}{|c|c|c|c|c|c|c|}
\hline PATHWAY & STUDY & ENERGY SOURCE & PROCESS & $\begin{array}{c}\mathbf{W T P}_{\text {Energy }} \\
\left(\frac{\mathbf{M J}_{\mathbf{J}}}{\mathbf{M J}_{\mathbf{f}}}\right)\end{array}$ & $\begin{array}{l}\mathbf{W T P}_{\mathbf{G H G s}} \\
\left(\frac{\mathbf{g C O}_{2 \mathrm{e}}}{\mathrm{MJ}}\right)\end{array}$ & CODE \\
\hline Con.NG (N1) & [15] & $\begin{array}{l}\text { (Coal + Raw NG+ Petro- } \\
\text { leum) }\end{array}$ & $\begin{array}{l}\text { Conventional } \\
\text { Raw NG to } \\
\text { NG }\end{array}$ & 1.15 & 137.81 & $\mathrm{NG}_{\text {Conv }}$ \\
\hline $\begin{array}{l}\text { Synthetic_CNG } \\
\text { (N2) }\end{array}$ & [1] & Wind Electricity & $\begin{array}{l}\text { Synthetic- } \\
\text { CNG }\end{array}$ & 1.04 & 3.3 & $\mathrm{CNG}_{\mathrm{SynNG}}$ \\
\hline
\end{tabular}

\subsubsection{Well-to-pump}

"H" and "N" refer to hydrogen and natural gas pathways. The letter is followed by a pathway number. This nomenclature was assigned for the simplicity of mentioning these HCNG pathways in Conclusions section. HN denotes HCNG pathway. For example, H1N1 means a mixture of gaseous hydrogen from central NG SMR and conventional NG. In the section Conclusions, the discussion has been done for only $0 \% \mathrm{HCNG}$ and $30 \% \mathrm{HCNG}$, as the vehicle performance with $15 \% \mathrm{HCNG}$ is not significant. 
Table 3: Description of gaseous hydrogen pathways for GREET modeling

\begin{tabular}{|c|c|}
\hline $\mathrm{GH}_{2}$ PATHWAY CODE & DESCRIPTION \\
\hline GH2_NG_CT_C_CN (H1) & Central Plants: NG or FG to Gaseous Hydrogen \\
\hline GH2_Solar_CT_C_CN (H2) & Central Plants: Solar Energy to Gaseous Hydrogen \\
\hline GH2_Nucl_CT_C_CN (H3) & Central Plants: Nuclear to Gaseous Hydrogen \\
\hline GH2_HTGR EC_CT_C_CN (H4) & Central Plants: Electrolysis (HTGR) to Gaseous Hydrogen \\
\hline GH2_Coal_CT_C_CN (H5) & Central Plants: Coal to Gaseous Hydrogen \\
\hline GH2_Bio_CT_C_CN (H6) & Central Plants: Biomass to Gaseous Hydrogen \\
\hline GH2_COG_CT_C_CN (H7) & Central Plants: Coke Oven Gas to Gaseous Hydrogen \\
\hline GH2_NG_RF_C_CN (H8) & Refueling Stations: NG or FG to Gaseous Hydrogen \\
\hline GH2_Elect_RF_C_CN (H9) & Refueling Stations: Electricity to Gaseous Hydrogen \\
\hline
\end{tabular}

\subsection{Governing equations}

After the complete set of data was obtained, integration of hydrogen and CNG pathways was necessary to calculate the combined result for $\mathrm{HCNG}$.

$\mathrm{k}_{\mathrm{HCNG}}=\frac{\% \text { of } \mathrm{H}_{2} * \mathrm{LHV}_{\mathrm{H}_{2}} * \mathrm{k}_{\mathrm{H}_{2}}+\% \text { of } \mathrm{CNG} * \mathrm{LHV}_{\mathrm{CNG}} * \mathrm{k}_{\mathrm{CNG}}}{\% \text { of } \mathrm{H}_{2} * \mathrm{LHV}_{\mathrm{H}_{3}}+\% \text { of } \mathrm{CNG} * \mathrm{LHV}_{\mathrm{CNG}}} ; \mathrm{LHV}-$ basis

(1)

$\mathrm{k}=$ Desired output parameters (LCI; for e. g. total energy, GHG, Lower heating value, etc. )

Note: ' $\mathrm{k}$ ' needed to be calculated for both stages of WTP and PTW and then can be integrated by the following way.

[6] suggested the integration of well-to-tank and tank-to-wheel results to combine and form well-to-wheel results.

$$
\begin{aligned}
& \mathrm{WTW}_{\text {Total Energy }}\left(\frac{\mathrm{MJ}}{\mathrm{km}}\right)=\operatorname{PTW}_{\text {Total Energy }}\left(\frac{\mathrm{MJ}}{\mathrm{km}}\right) *\left(1+\mathrm{WTP}_{\text {Total Energy }}\left(\frac{\mathrm{MJ}}{\mathrm{MJ}}\right)\right) \\
& \mathrm{WTW}_{\mathrm{GHG}}\left(\frac{\mathrm{gCO}_{2 \mathrm{eq}}}{\mathrm{km}}\right)=\operatorname{PTW}_{\mathrm{GHG}}\left(\frac{\mathrm{gCO}_{2 \mathrm{eq}}}{\mathrm{km}}\right)+\mathrm{PTW}_{\text {Total Energy }}\left(\frac{\mathrm{MJ}}{\mathrm{km}}\right) * \mathrm{WTP}_{\mathrm{GHG}}\left(\frac{\mathrm{gCO}_{2 e q}}{\mathrm{MJ}_{\text {fuel }}}\right) \\
& \text { WTP LCI }{ }_{\mathrm{xHCNG}}=\frac{\mathrm{x} * \mathrm{LHV}_{\mathrm{H}_{2}} * \mathrm{WTP} \mathrm{LCI}_{\mathrm{H}_{2}}+(1-\mathrm{x}) * \mathrm{LHV}_{\mathrm{CNG}} * \mathrm{WTP} \mathrm{LCI} \mathrm{CNG}_{\mathrm{CN}}}{\mathrm{x} * \mathrm{LHV}_{\mathrm{H}_{2}}+(1-\mathrm{x}) * \mathrm{LHV}_{\mathrm{CNG}}} \\
& \text { PTW LCI }{ }_{\mathrm{xHCNG}}=\frac{\mathrm{x} * \mathrm{LHV}_{\mathrm{H}_{2}} * \mathrm{PTW} \mathrm{LCI}_{\mathrm{H}_{2}}+(1-\mathrm{x}) * \mathrm{LHV}_{\mathrm{CNG}} * \mathrm{PTW} \mathrm{LCI}_{\mathrm{CNG}}}{\mathrm{x} * \mathrm{LHV}_{\mathrm{H}_{2}}+(1-\mathrm{x}) * \mathrm{LHV}_{\mathrm{CNG}}}
\end{aligned}
$$

Where $\mathrm{x}=$ fraction of hydrogen in HCNG (e.g. 0.15 for $15 \%$ hydrogen)

\section{RESULTS AND DISCUSSION}

The results were divided into three main categories for the demonstration. The brown color represents baseline $\mathrm{CNG}$, light green represents $15 \% \mathrm{HCNG}$ and dark green represents $30 \% \mathrm{HCNG}$. Two sets of results: WTP and WTW were presented here; for each baseline pathway of natural gas with a series of HCNG pathways. In the first part, various $15 \% \mathrm{HCNG} \& 30 \% \mathrm{HCNG}$ pathways were compared with baseline $\mathrm{CNG}$ (from conventional natural gas) whereas, in the second part, $\mathrm{HCNG}$ pathways were compared with baseline synthetic CNG. 


\subsection{Well-to-pump energy \& emission analysis}
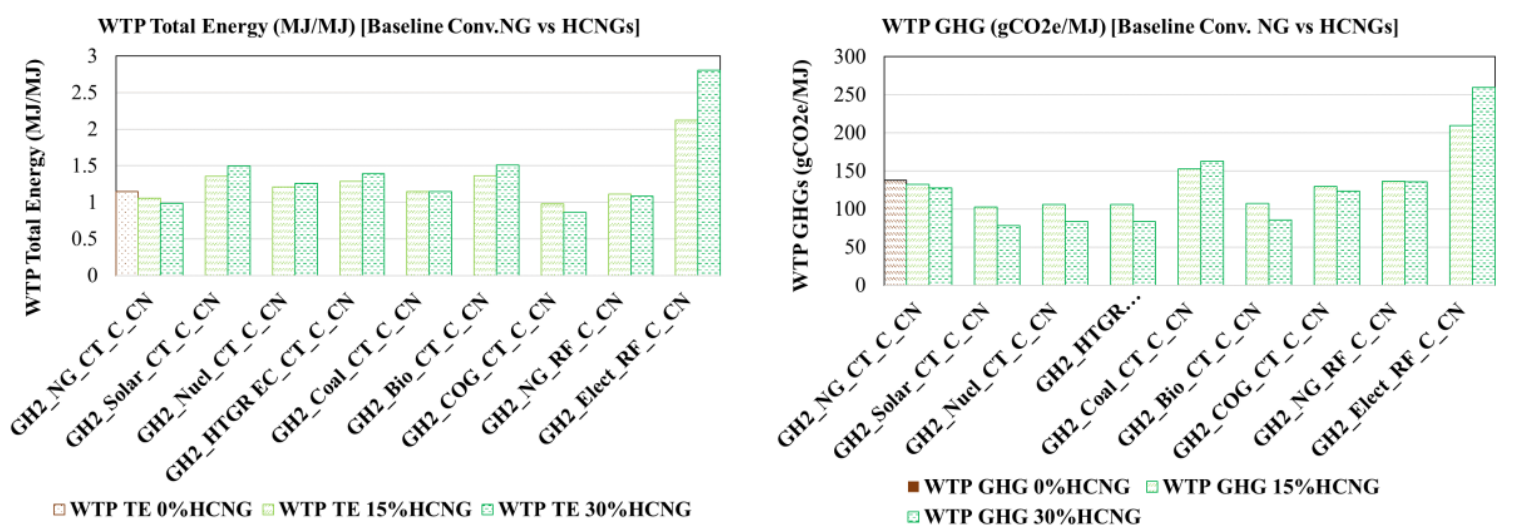

Figure 3 (a): WTP Total Energy (Baseline Conv.NG)

(b) WTP GHG (Baseline Conv.NG)
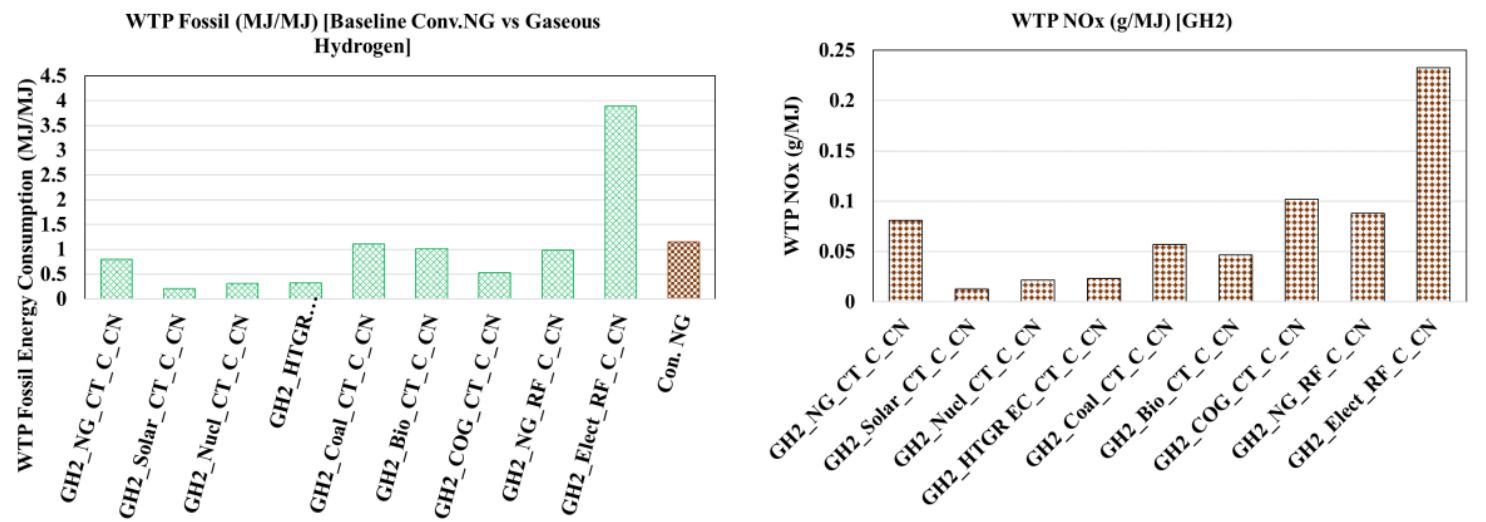

Figure 4 (a): WTP Fossil Energy (Conv.NG \& GH2 pathways) (b) WTP NOx (Gaseous hydrogen pathways)

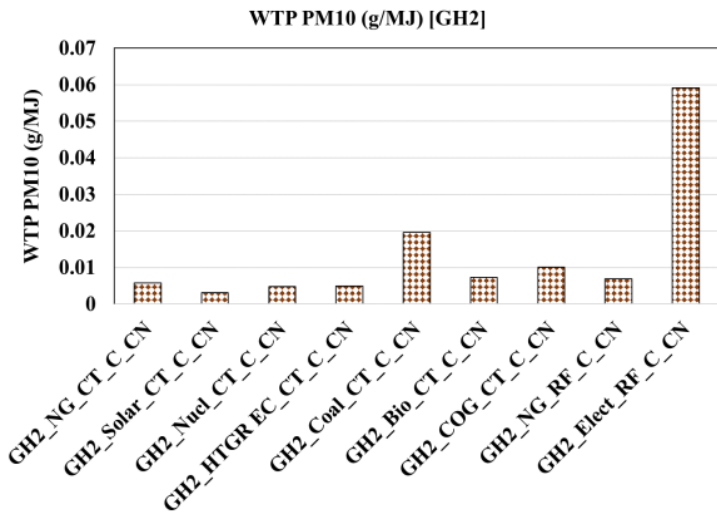

Figure 5 (a): WTP PM10 (GH2 pathways)

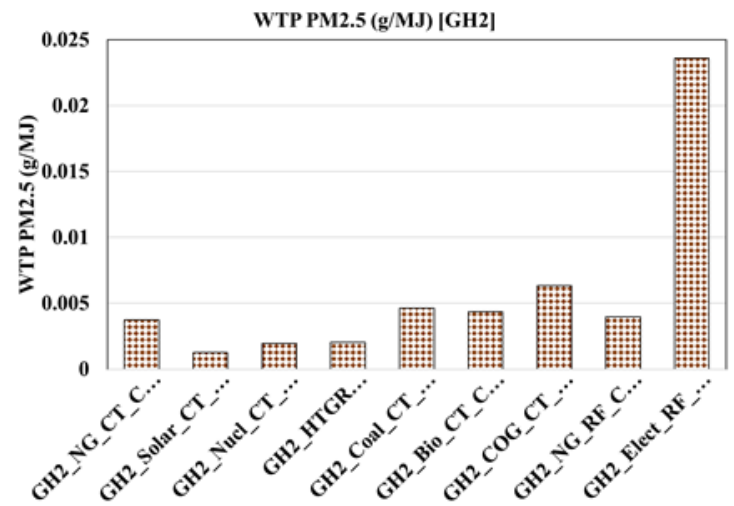

(b) WTP PM2.5 (GH2 pathways)

Figure 3 shows the well-to-pump energy use and GHG emission for $0 \%, 15 \%$ and $30 \% \mathrm{HCNG}$ pathways with CNG from conventional natural gas and hydrogen from the various feedstock. Figure 4 (a) shows the fossil energy intensity of gaseous hydrogen pathways compared with conventional natural gas and Figure 4 (b) shows the NOx emissions for various gaseous hydrogen pathways compared with conventional gasoline. Similarly, Figure 5 shows the well-to-pump PM emissions for various pathways of gaseous hydrogen. These calculations were performed by GREET simulation with localized parametric data assumptions to relate this study in the context of China. Figure 3, Figure 4, and Figure 5 claimed that 
compared with conventional natural gas, HCNG pathways have cleaner and lower energy intensity especially for renewable pathways such as biomass, solar and nuclear energy. Coke oven gas is a surplus by-product from coking plants in China and possesses dual benefits of lower energy consumption and lower GHG emission.

\subsection{Well-to- wheel total energy \& ghg emission analysis}

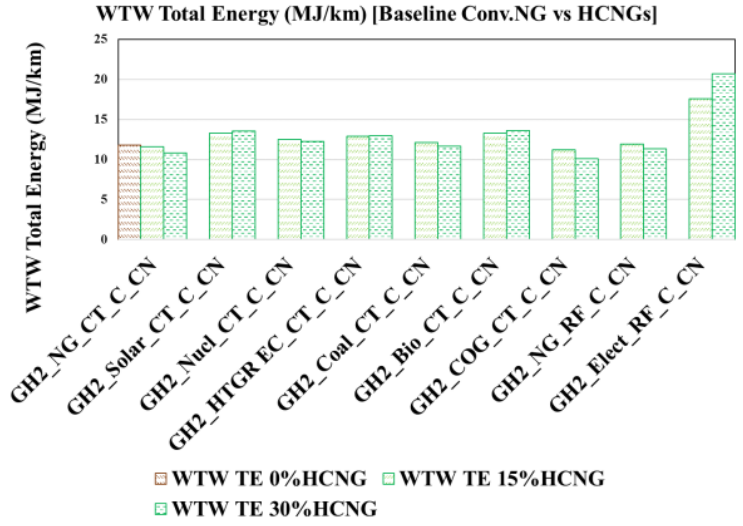

Figure 6 (a): WTW Total Energy (Baseline Conv.NG)

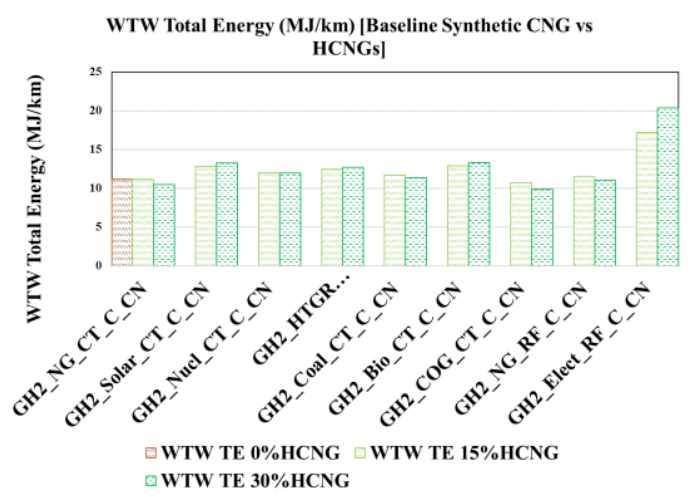

Figure 7 (a): WTW Total Energy (Baseline Syn.CNG)

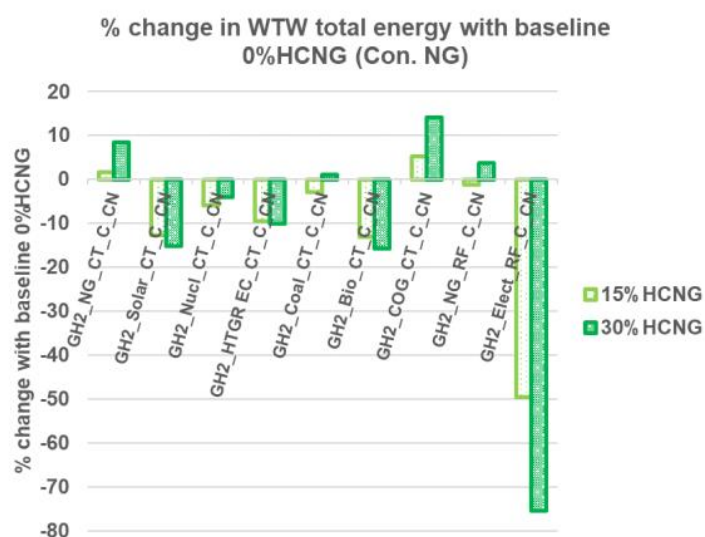

WTW GHG (gCO2e/km) [Baseline Conv.NG vs HCNGs]

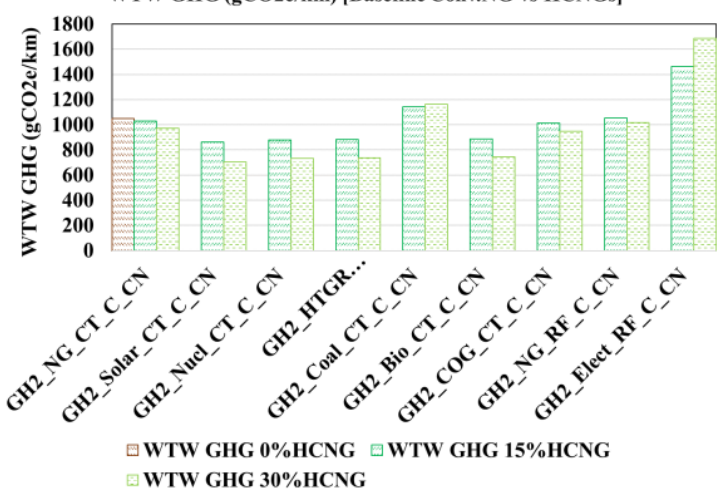

(b) WTW GHG (Baseline Conv.NG)

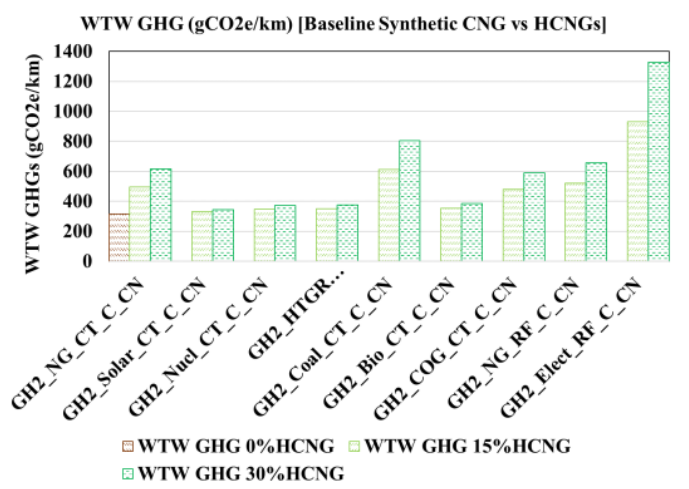

(b) WTW GHG (Baseline Syn.CNG)

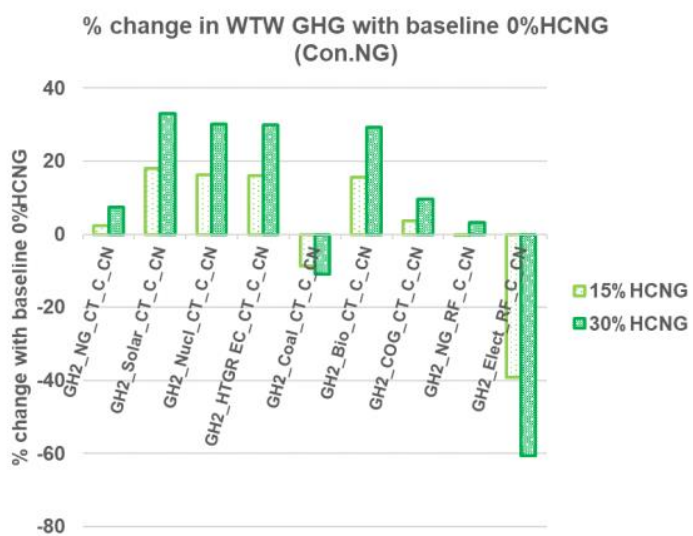

Figure 8: \% Change in WTW total energy \& WTW GHG with baseline 0\%HCNG (Conv.NG)

Figure 6 and Figure 7 illustrate the well-to-wheel results calculated for comparison of various HCNGs pathways and a CNG pathway based on total energy per vehicle $\mathrm{km}$ and total grams of $\mathrm{CO}_{2 \text {,equivalent per }}$ vehicle km. Although HCNGs showed better pump-to-wheel characteristics due to hydrogen enrichment, still natural gas remained a major constituent in the mixture fuel HCNG. Hydrogen is just an energy carrier used 
as a supplement fuel. Therefore, the natural gas pathways showed a significant effect on total WTW LCI use. This was the reason synthetic CNG was compared with different HCNGs pathways (15\% and 30\% HCNG). LCI refers to energy use and GHG emitted and is known as life cycle inventory according to the ISO 14040 guidelines of LCA.

The baseline vehicle option is $0 \% \mathrm{HCNG}$ which means only CNG. The two pathways of CNG were considered in this study such as conventional and synthetic CNG which signify two different scenarios. Figure 8 shows the \% change in WTW total energy and \% change in WTW GHG with baseline Conv.NG which is the horizontal line. The positive \% change signifies 'decrement' compared with baseline whereas negative \% signifies 'increment' compared with baseline. The desired goal was a decrement in energy consumption which can be termed as 'energy saving' and decrement in GHG termed as 'reduced GHG'. So, the alternative HCNG options lying above the $\mathrm{x}$-axis are desirable and higher is the magnitude, higher is the effectiveness and benefits of energy saving and reduced GHG.

The hydrogen blend 30\% with conventional compressed natural gas (Conv.NG) decreased well-towheel GHG emission compared with 0\%HCNG (Conv.NG) by $32.982 \%, 29.275 \%$, and $9.694 \%$ with hydrogen pathways such as solar, biomass, and coke oven gas, respectively. On the other hand, for the same operation, the well-to-wheel total energy was increased by $15.176 \%$, and $15.719 \%$ for solar and biomassbased pathways respectively. However, although the energy consumption was increased for solar and biomass-based $15 \% \mathrm{HCNG}$ and $30 \% \mathrm{HCNG}$ pathways compared with $0 \% \mathrm{HCNG}$, the feedstock used was renewable and qualitatively cleaner. Coke oven gas based $30 \% \mathrm{HCNG}$ pathway reduces the WTW energy consumption by $9.694 \%$ compared with $0 \% \mathrm{HCNG}$. The worst scenario was found in the form of $30 \% \mathrm{HCNG}$ with grid electrolysis pathway which showed $60.648 \%$ increment in WTW GHG and $75.479 \%$ increment in WTW total energy compared with baseline $0 \% \mathrm{HCNG}$ (conventional CNG). The booming renewable electricity generation and availability of a tremendous amount of coke oven gas as by-products of coking industries in China establishes a prospective platform for sustainable hydrogen economy in China and is supposed to promote the commercialization of HCNG use in future. Comparing Figure 6 and Figure 7, it is evident that replacing conventional natural gas with a synthetic $\mathrm{CNG}$ gas can further decrease the energy use and GHG emission as it is lesser carbon-intensive and energy intensive.

The synthetic CNG mentioned here is produced by using wind electricity. The pump-to-wheel data showed only $0.91 \%$ improvement in fuel economy for $30 \% \mathrm{HCNG}$ whereas increasing fuel consumption by $2.92 \%$ for $15 \% \mathrm{HCNG}$ compared with $0 \% \mathrm{HCNG}$. This contrasts the results presented by [11] which demonstrated a 7\% decrease in fuel consumption and a 11\% reduction in GHGs during HDV operation with $20 \% \mathrm{HCNG}$. The reason is that the pump-to-wheel data used here was quite old and a series of R\&D works recently has improved the performance and emission to a larger extent than before. The reason for considering this pump-to-wheel data is in this LCA study is because of its originality and existence as a real demonstration of HCNG vehicle. Another study [4] demonstrated $11 \%$ reduction in fuel consumption and a $21 \%$ reduction in GHG emission for $30 \% \mathrm{HCNG}$ compared with CNG as per European codes of fuel consumption analysis.

The well-to-pump energy use for hydrogen production by NG SMR in the study [8] showed 1.10, 1.13 , and $1.16 \mathrm{MJ} / \mathrm{MJ}$, respectively for $0 \%, 15 \%$, and $30 \% \mathrm{HCNG}$ which in our finding is $1.02,1.11$, and 1.08 $\mathrm{MJ} / \mathrm{MJ}$ total energy use for natural gas-to-hydrogen pathways of $0 \% \mathrm{HCNG}, 15 \% \mathrm{HCNG}$ and $30 \% \mathrm{HCNG}$ at refueling station. This validated that the modeled results made sense for this pathway as well as other pathways. As there is not much work done on LCA of HCNG vehicles in China, it is hard to find the data for validation of the results obtained here as well as difficult to compare our WTW results with other studies. It is evident from Figure 6 and Figure 7 that the natural gas based pathways have the best energy efficiency, grid electrolysis as the worst and coal-to-hydrogen in between these. Coke oven gas-to-hydrogen pathways can be the best choice for both $15 \% \mathrm{HCNG}$ and $30 \% \mathrm{HCNG}$ options due to the dual benefits of lower energy use and GHG emission. Comparing Figure 6 and Figure 7, it is clearly evident that operating vehicles entirely with synthetic CNG is lesser energy and GHG intensive as compared with every $15 \% \mathrm{HCNG}$ and $30 \% \mathrm{HCNG}$ pathways which is quite optimistic as it is rare to find the exploration of synthetic CNG in a country like China on a very large scale.

\section{CONCLUSIONS}

In this research work, our significant contribution included a collection of localized input data for GREET simulation in order to evaluate the well-to-pump data of energy use, fossil energy use, GHG emitted and air pollutant emissions in the context of China. Secondly, the integration of well-to-pump results of hydrogen 
and CNG was achieved on a weighted average principle which is a simplified way which can be used for other studies involving a blend of different fuels such as hydrogen-methanol, hydrogen-gasoline, etc.

The general conclusion that can be drawn from Figure 6 summarized in terms of best-to-worst scenarios of total energy and GHG emissions.

\section{GHG Emission: H2N1(best) $<\mathrm{H} 3 \mathrm{~N} 1<\mathrm{H} 4 \mathrm{~N} 1<\mathrm{H} 6 \mathrm{~N} 1<\mathrm{H} 7 \mathrm{~N} 1<\mathrm{H} 1 \mathrm{~N} 1<\mathrm{H} 8 \mathrm{~N} 1<\mathrm{N} 1<\mathrm{H} 5 \mathrm{~N} 1<\mathrm{H} 9 \mathrm{~N} 1$ (worst)}

Total Energy: H7N1(best) $<\mathrm{H} 1 \mathrm{~N} 1<\mathrm{H} 8 \mathrm{~N} 1<\mathrm{H} 5 \mathrm{~N} 1<\mathrm{N} 1<\mathrm{H} 3 \mathrm{~N} 1<\mathrm{H} 4 \mathrm{~N} 1<\mathrm{H} 2 \mathrm{~N} 1<\mathrm{H} 6 \mathrm{~N} 1<\mathrm{H} 9 \mathrm{~N} 1$ (worst)

The 30\%HCNG pathways except $\mathrm{H} 5 \mathrm{~N} 1$ and $\mathrm{H} 9 \mathrm{~N} 1$ showed lower well-to-wheel GHG emissions compared with baseline $0 \% \mathrm{HCNG}$ (N1). Additionally, 30\%HCNG pathways such as H7N1, H1N1, H8N1, and H5N1 showed lower well-to-wheel energy consumption compared with baseline 0\%HCNG (N1). The exact increase and decrease amount with baseline $0 \% \mathrm{HCNG}$ or N1 were shown in Figure 8. Hence, it can be concluded that solar, biomass and coke oven gas based 30\%HCNG pathways have dual benefits of lower GHG emissions and lower energy consumption compared with $0 \%$ HCNG (Conventional NG only) on an entire well-to-wheel fuel cycle scale. Even though the energy consumption might be slightly higher for $30 \% \mathrm{HCNG}$ pathways based on solar and biomass compared with $0 \% \mathrm{HCNG}$, the sources of feedstock are renewable in case of the solar pathway and usually organic wastes or agricultural by-products in case of biomass. As China has a tremendous amount of coke oven gas from coking and steel industries as byproducts, it possesses a great prospect of hydrogen production in large quantity in a near-term future.

\section{ACKNOWLEDGMENTS}

I would like to present my heartfelt thanking the people who have supported and helped me so much throughout this period. The first thank goes to my mentor Prof. Ma Fanhua at Department of Automotive Engineering, Tsinghua University, who helped me throughout the completion of this research work. This work could have never taken the same form without his contribution. Secondly, I would like to extend my thankfulness to Prof. Zhuge Weilin who provided me lots of encouragement, emotional support, and flexibility at my work. I would also sincerely like to thank Prof. Wu Ye of School of Environment at Tsinghua University who helped me to transform my ideas into a well-structured realism through his interactions with me based on a multi-disciplinary area related to 'Environment and Energy' issues.

Moreover, Mrs. Xiaoyi He, a Ph.D. scholar of School of Environment at Tsinghua University who always stood upright and helped me whenever I had any questions. I would also like to thank my parents and my entire family for their wise counsel and a sympathetic ear. Without my parent's tireless efforts and hardships, patience, selfless and boundless affection, this work would have never been possible. Special thanks go to my dad who is my role model, and a source of inspiration for me.

\section{BIBLIOGRAPHY}

[1] CONCAWE, E., Well-to-tank report version 4.0, JEC well-to-wheel analysis, Well-to-tank report, Institute for Energy and Transport, Joint Research Centre, 2006.

[2] DENG, X., WANG, H., HUANG, H., et al., "Hydrogen flow chart in China”, International journal of hydrogen energy, v.35, pp. 6475-6481, 2010.

[3] GENOVESE, A., CONTRISCIANI, N., ORTENZI, F., et al., "On road experimental tests of hydrogen/natural gas blends on transit buses", International journal of hydrogen energy, v.36, pp. 17751783,2011

[4] HAN, J., CHAE, J., LEE, T., KO, K., “Analysis of Fuel Consumption of HCNG Bus for US and European Test Codes”, International Journal of Applied Engineering Research, v.12, pp. 8232-8237, 2017

[5] HUANG, Z., ZHANG, X., "Well-to-wheels analysis of hydrogen based fuel-cell vehicle pathways in Shanghai”, Energy, v.31, pp. 471-489, 2006

[6] JRC, R. E., HASS, H., LARIVÉ, J.-F., et al., WELL-TO-WHEELS Report Version 4. a JEC WELL-TOWHEELS ANALYSIS, Institute for Energy and Transport, Joint Research Centre, Luxembourg: Publications Office of the European Union, 2014, 2014.

[7] KARNER, D., BRAYER, R., Hydrogen and Hydrogen/Natural Gas Station and Vehicle Operations-2006 Summary Report, Idaho National Laboratory (INL), Idaho Falls, Idaho 83415, 2006.

[8] KILGUS, D., Life Cycle Assessment of a Demonstration Project, Department of Energy and Environment, Division of Environmental Systems Analysis, vol Master's, Chalmers University OF 
Technology, Göteborg, Sweden, 2005, 2005.

[9] LYU, C., OU, X., ZHANG, X., "China automotive energy consumption and greenhouse gas emissions outlook to 2050", Mitigation and Adaptation Strategies for Global Change, v.20, pp. 627-650, 2015

[10] MA, F., NAEVE, N., WANG, M., et al., Hydrogen-enriched compressed natural gas as a fuel for engines, Natural Gas, InTech, 2010.

[11] MA, F., WANG, Y., DING, S., et al., "Twenty percent hydrogen-enriched natural gas transient performance research", International journal of hydrogen energy, v.34, pp. 6523-6531, 2009

[12] MEHRA, R. K., DUAN, H., JUKNELEVIČIUS, R., MA, F., et al., "Progress in hydrogen enriched compressed natural gas (HCNG) internal combustion engines-A comprehensive review", Renewable and Sustainable Energy Reviews, v.80, pp. 1458-1498, 2017

[13] NELSSON, C., HULTEBERG, C., SAINT-JUST, J., et al., HCNG-A Dead End or a Bridge to the Future?, 18th World Hydrogen Energy Conference. Essen, v. 38, Schriften des Forschungszentrums Jülich / Energy \& Environment, Essen, 2010.

[14] OU, X., ZHANG, X., CHANG, S., "Alternative fuel buses currently in use in China: life-cycle fossil energy use, GHG emissions and policy recommendations”, Energy Policy, v.38, pp. 406-418, 2010

[15] OU, X., ZHANG, X., ZHANG, X., et al., "Life cycle GHG of NG-based fuel and electric vehicle in China”, Energies, v.6, pp. 2644-2662, 2013

[16] SINGH, S., MATHAI, R., SINGH, V., et al., "Effect of Hydrogen on the Performance \& Emission Characteristics of a 6.0 L Heavy Duty Natural Gas Engine”, SAE International, 2014.

[17] TEMIZER, M., China leads with most natural gas vehicles, 2018.

[18] UNICH, A., MORRONE, B., MARIANI, A., et al., "The impact of natural gas-hydrogen blends on internal combustion engines performance and emissions", SAE International, 2009

[19] ZHOU, N., FRIDLEY, D., MCNEIL, M., et al., China's energy and carbon emissions outlook to 2050, Ernest Orlando Lawrence Berkeley National Laboratory, Berkeley, CA (US), Berkeley National Laboratory, 2011.

\section{ORCID}

Pralhad Gupta

https://orcid.org/0000-0002-3840-2414

$\mathrm{Ye} \mathrm{Wu}$ https://orcid.org/0000-0002-9928-1177

Xiaoyi He https://orcid.org/0000-0002-6263-0329

Weilin Zhuge https://orcid.org/0000-0002-9023-6564

Fanhua Ma https://orcid.org/0000-0001-8971-789X 


\section{APPENDIX 1 ABBREVIATIONS}

\begin{tabular}{|c|c|}
\hline WTW & Well-to-Wheel \\
\hline WTP & Well-to-Pump \\
\hline PTW & Pump-to-Wheel \\
\hline LCA & Life Cycle Analysis \\
\hline $\mathrm{LCI}$ & Life Cycle Inventory \\
\hline LCIA & Life Cycle Impact Assessment \\
\hline HCNG & hydrogen-enriched compressed natural gas \\
\hline US EPA & nited States Environmental Protection Agency \\
\hline $\mathrm{SI} / \mathrm{CI}$ & Spark-Ignition/ Compression Ignition \\
\hline HDT/MDT/LDT & Heavy-Duty Trucks/Medium-Duty trucks/ Light-Duty Trucks \\
\hline GDP & Gross Domestic Product \\
\hline IPCC & Intergovernmental Panel on Climate Change \\
\hline NGV & Natural Gas Vehicle \\
\hline CNG/LNG & Compressed Natural Gas/ Liquefied Natural Gas \\
\hline IEA & International Energy Agency \\
\hline $\mathrm{AFV}$ & Alternative Fueled Vehicles \\
\hline $\mathrm{H} / \mathrm{C}$ & ratio hydrogen-to-carbon ratio \\
\hline EEV & Enhanced Environmentally Friendly \\
\hline TWC & Three-Way Catalyst \\
\hline NEDC & New European Driving Cycle \\
\hline PFI & Port-Fuel Injection \\
\hline AFR & Air-to-Fuel Ratio \\
\hline FCV & Fuel Cell Vehicle \\
\hline EVs & Electric Vehicles \\
\hline NG & Natural Gas \\
\hline $\mathrm{CNG}$ & Compressed Natural Gas \\
\hline ETC & European Transient Cycle \\
\hline WHTC & World Harmonized Transient Cycle \\
\hline GVW & Gross Vehicle Weight \\
\hline GHG & Greenhouse Gases \\
\hline GWP & Global Warming Potentials \\
\hline $\mathrm{LHV} / \mathrm{HHV}$ & Lower Heating Value/ Higher Heating Value \\
\hline $\mathrm{CCS}$ & Carbon Capture \& Storage \\
\hline NMHC & Non-Methane Hydrocarbons \\
\hline $\mathrm{CO}_{2}$ & Carbon dioxide \\
\hline $\mathrm{NO}_{\mathrm{x}}$ & Nitrogen Oxides \\
\hline $\mathrm{SO}_{\mathrm{x}}$ & Sulphur Oxides \\
\hline $\mathrm{CO}$ & Carbon Monoxide \\
\hline BSFC & Brake Specific Fuel Consumption \\
\hline VOC & Volatile Organic Compounds \\
\hline $\mathrm{SO}_{2}$ & Sulfur Dioxide \\
\hline $\mathrm{CH}_{4}$ & Methane \\
\hline $\mathrm{HC}$ & Hydrocarbons \\
\hline
\end{tabular}

\section{APPENDIX 2 NOMENCLATURE}
$\mathrm{GH}_{2}$ : Gaseous Hydrogen
$\mathrm{LH}_{2}$ : Liquid Hydrogen
CT: Central Station
RF: Refueling Station
C: Current Technology 
F: Future Technology

CY: with CCS

$\mathrm{CN}$ : without CCS

WTP TE: Well-to-pump total energy (MJ) per MJ of fuel

WTW TE: Well-to-wheel total energy (MJ) per kilometer vehicle distance traveled

WTP GHG: Well-to-pump greenhouse gas emissions (grams of $\mathrm{CO} 2$ equivalent) per MJ of fuel

WTW GHG: Well-to-wheel greenhouse gas emissions (grams of $\mathrm{CO} 2$ equivalent) per kilometer vehicle distance traveled

$\mathrm{x}$ : fraction of hydrogen in $\mathrm{HCNG}$

$\mathrm{k}$ : life cycle inventory (LCI)

Conv.NG: Conventional Natural Gas

$\mathrm{gCO}_{2 \mathrm{eq}}$ : grams of carbon-dioxide equivalent

$\mathrm{MJ}_{\mathrm{f}}$ : Megajoules of energy in the finished fuel

Km: kilometers

MJ: Megajoules

APPENDIX 3

$30 \%$ HCNG pathways

H2N1, H3N1, H4N1, H6N1, H7N1, H1N1, H8N1, H5N1, H9N1

0\%HCNG Pathways

N1: Conventional Natural Gas

\begin{tabular}{l|l}
\hline 30\% HCNG PATHWAY CODE & DESCRIPTION \\
\hline H1N1 & Central Plants: NG or FG to Gaseous Hydrogen+ Conventional Natural Gas \\
\hline H2N1 & Central Plants: Solar Energy to Gaseous Hydrogen+ Conventional Natural Gas \\
\hline H3N1 & Central Plants: Nuclear to Gaseous Hydrogen+ Conventional Natural Gas \\
\hline H4N1 & Central Plants: Electrolysis (HTGR) to Gaseous Hydrogen+ Conventional Natural Gas \\
\hline H5N1 & Central Plants: Coal to Gaseous Hydrogen+ Conventional Natural Gas \\
\hline H6N1 & Central Plants: Biomass to Gaseous Hydrogen+ Conventional Natural Gas \\
\hline H7N1 & Central Plants: Coke Oven Gas to Gaseous Hydrogen+ Conventional Natural Gas \\
\hline H8N1 & Refueling Stations: NG or FG to Gaseous Hydrogen+ Conventional Natural Gas \\
\hline H9N1 & Refueling Stations: Electricity to Gaseous Hydrogen+ Conventional Natural Gas \\
\hline
\end{tabular}

